\title{
Colonization of Durum Wheat (Triticum turgidum L. var. durum) Culms Exhibiting Premature Senescence (Dead Heads) Associated with Fusarium pseudograminearum Crown Rot
}

Noel L. Knight, ${ }^{\dagger}$ Centre for Crop Health, Faculty of Health, Engineering and Sciences, University of Southern Queensland, Toowoomba, QLD, Australia, 4350; Bethany Macdonald, Queensland Department of Agriculture and Fisheries, Leslie Research Centre, Toowoomba, QLD, Australia 4350; and Mark W. Sutherland, Centre for Crop Health, Faculty of Health, Engineering and Sciences, University of Southern Queensland, Toowoomba, QLD, Australia, 4350

\begin{abstract}
Fusarium crown rot is a significant disease of durum wheat (Triticum turgidum L. var. durum), which exhibits high levels of disease susceptibility. The most extreme symptom of crown rot is a prematurely senescing culm that typically fails to set grain. Individual crown rotaffected durum wheat plants displaying both nonsenescent and prematurely senescent culms were harvested to compare visual discoloration, Fusarium pseudograminearum biomass, and vascular colonization in culm sections sampled at three different heights above the crown. Field samples of EGA Bellaroi were collected at Wellcamp, QLD, in 2011, 2012, 2013, and 2014, and of Hyperno at Narrabri, NSW, in 2014.

Prematurely senescent culms exhibited greater visual discoloration, $F$. pseudograminearum biomass, and vascular colonization than nonsenescent culms in each year they were examined. The extent of these differences varied between environments and timing of collection in each year. Vascular colonization initially occurred in xylem vessels and spread into phloem tissues as disease severity increased. The increased presence of hyphae in vascular bundles of prematurely senescing culms provides strong evidence for the hypothesis that restriction of water and nutrient movement in a diseased culm is a key factor in crown rot severity.
\end{abstract}

Crown rot, caused by Fusarium pseudograminearum (O'Donnell \& T. Aoki) or F. culmorum (W.G. Smith) Sacc., is a significant disease of winter cereals worldwide (Burgess et al. 2001). Symptoms are typically reported as honey brown lesions appearing on leaf sheaths, internodes, and nodal tissues (Burgess et al. 2001). Another frequently reported, but not necessarily unique, symptom of crown rot is a prematurely senescing culm. These are typically single culms of a plant identified by an early loss of greenness in the inflorescence, proceeding into the peduncle (Sims et al. 1961; Wallwork 2000). These have historically been referred to as 'dead heads' or 'white heads.' These heads either contain shriveled grain or are completely empty (Sims et al. 1961). While these symptoms are widely used in assessing field trials for crown rot severity, the specific etiology of their development has not been delineated (Burgess et al. 1975; Hollaway and Exell 2010; Klein et al. 1991; McKnight and Hart 1966; Purss 1966). Burgess et al. (2001) has suggested that prematurely senescing culm formation is largely dependent on soil moisture, with low moisture environments presumably leading to disruption of water transport from the seminal root system to the head due to fungal colonization. However the pathophysiological process of prematurely senescing culm development has not been directly investigated.

Knight and Sutherland $(2012 ; 2016)$ have recently reported on the infection pathways and target tissues for $F$. pseudograminearum during infections of cereal hosts. These authors described the growth of $F$. pseudograminearum through seedling leaf sheaths, with initial penetration frequently occurring through stomata, followed by colonization of the leaf sheath tissues. Growth through the leaf sheaths led to penetration into culm tissues and eventual growth of hyphae into xylem and phloem tissues of the vascular bundles in adult plants. Additionally, colonization of prematurely senescing culms was briefly examined and shown to be more extensive than other colonized culms that did not exhibit premature senescence.

${ }^{\dagger}$ Corresponding author. E-mail: noel.knight@outlook.com

Accepted for publication 4 June 2017.

() 2017 The American Phytopathological Society
While the development and presence of prematurely senescing culms is influenced by the environment and can vary between host genotypes (Purss 1966), they can potentially be useful indicators of disease consequences. For example, Klein et al. (1991) reported a significant positive correlation between prematurely senescing culm incidence and loss in potential grain yield, indicating that prematurely senescing culm incidence could be used to give an approximation of yield loss. Another study by Hollaway and Exell (2010) measured the incidence and severity of crown rot across western Victoria from 1997 to 2009 by recording the occurrence of prematurely senescing culms.

It has been estimated that in Australia, crown rot of wheat causes yield losses worth an average of $\$ 79$ million per annum (Murray and Brennan 2009). In comparison with the hexaploid spring wheats (Triticum aestivum L.), which have at best only partial levels of resistance, the tetraploid durum wheats (T. turgidum L. var. durum) are considered to be highly susceptible to crown rot, with no significant levels of disease resistance having been identified (Martin et al. 2013). The difference in resistance between the species can be highlighted using a nine point rating scale from resistant (1) to very susceptible (9), with the best crown rot reaction available in commercial spring wheat cultivars in Australia being moderately resistant to moderately susceptible (4), compared with the best commercial durum wheat cultivars being susceptible to very susceptible (8) (Matthews et al. 2016). Recently, wheat geneticists have successfully introduced improved crown rot resistance from spring wheats into elite durum lines via hexaploid/tetraploid crosses and then selected in subsequent generations for tetraploid progeny with improved disease performance. These selections are currently being evaluated in commercial breeding programs (Martin et al. 2013).

This current study compares nonsenescent and prematurely senescent diseased culms in an attempt to elucidate fundamental colonization processes associated with crown rot disease. Assessment of prematurely senescent culm formation was selectively targeted in durum wheat cultivars due to their disease susceptibility and the common occurrence of prematurely senescent culms in the field. It was hypothesized that prematurely senescent culms would have greater visual discoloration, $F$. pseudograminearum biomass, and colonization of vascular tissues than nonsenescent culms. The information 
generated will inform new disease severity assessment methods to characterize host reactions to crown rot.

\section{Materials and Methods}

Cultivars and field planting. Samples of durum wheat EGA Bellaroi (VS: very susceptible to crown rot [Matthews et al. 2016]) were collected from experimental fields in 2011, 2012, 2013, and 2014 at the Leslie Research Facility experimental farm at Wellcamp, QLD, and samples of the durum wheat Hyperno (S-VS: susceptiblevery susceptible to crown rot [Matthews et al. 2016]) were collected from an experimental field in 2014 from the Plant Breeding Institute at Narrabri, NSW (Table 1). The Wellcamp field site preparation, planting, inoculum production, and inoculation were as described by Knight and Sutherland (2015). The field site had been maintained on a three year rotation, where a year of fallow was followed by a crop of inoculated durum wheat (EGA Bellaroi) that was incorporated at maturity. In the third year, experimental field trials were sown. Samples of EGA Bellaroi were collected in year 2 or 3 of the rotation. The Wellcamp field contained natural and artificial inoculum. The inoculum of $F$. pseudograminearum, containing a mixture of aggressive Australian isolates grown on colonized millet (Pennisetum glaucum [L.] R. Br.), was produced by staff at the Leslie Research Facility (Toowoomba, QLD) following the procedure reported in Percy et al. (2012) and delivered to each furrow at planting via a fertilizer applicator. Inoculum was delivered at a rate of $2.5 \mathrm{~g} / \mathrm{m}$ in a band lying $1.5 \mathrm{~cm}$ above the seed.

The Narrabri site was under a long-term crown rot experimental trial/durum rotation from 2005 to 2015. Seeds of Hyperno were planted into uncultivated wheat stubble at a depth of $2.5 \mathrm{~cm}$ without artificial inoculum. The samples of Hyperno were taken during the durum rotation, which is used to increase $F$. pseudograminearum inoculum for experimental trials in the next season.

Plant selection and culm processing. Individual plants of EGA Bellaroi were selected at early to medium milk and Hyperno at soft to hard dough stages of development from the field based on the presence of at least one prematurely senescing culm and one nonsenescent culm of similar developmental stages. The identification of prematurely senescent culms was performed by assessing both seed formation and the change in culm coloration. Culms were considered prematurely senescent when a loss of greenness was observed in the head, sometimes extending further into the peduncle. Culms from each plant were separated, their position in the plant recorded, and the leaf sheaths and roots were removed. Each culm was sectioned into three $6-\mathrm{cm}$ portions, starting at the culm base and extending up to $18 \mathrm{~cm}$. Culms from 2012, 2013, and 2014 (Wellcamp and Narrabri) also had $6 \mathrm{~cm}$ of peduncle sampled from directly below the base of the rachis. All samples were stored at $-70^{\circ} \mathrm{C}$ before processing.

Culm tissues were dried, cut into small sections, and then dried again at $50^{\circ} \mathrm{C}$ overnight, before being ground to a powder in a FastPrep-24 instrument (MP Biomedicals, Seven Hills, NSW). Subsamples of these ground tissues, weighing 15 to $20 \mathrm{mg}$, were collected for DNA extraction. Genomic DNA was extracted using a Wizard Genomic DNA Extraction Kit (Promega, Sydney, NSW) following the plant DNA extraction protocol provided with the kit. Samples were eluted into $100 \mu \mathrm{l}$ of autoclaved high purity water and stored at $-20^{\circ} \mathrm{C}$ until required.

Dual-labeled probe PCR conditions. The polymerase chain reaction (PCR) procedure was as described in Knight et al. (2012). Briefly, multiplex real-time quantitative PCR was performed in a Rotor-Gene 6000 (Corbett Life Sciences, Sydney, NSW). Thermal cycling conditions consisted of $10 \mathrm{~min}$ at $95^{\circ} \mathrm{C}$ and then 35 cycles of $95^{\circ} \mathrm{C}$ for $15 \mathrm{~s}$ and $64^{\circ} \mathrm{C}$ for $1 \mathrm{~min}$. Reactions were performed in $20-\mu \mathrm{l}$ volumes containing autoclaved high purity water, 0.5 units Immolase DNA polymerase (Bioline, Alexandria, NSW), $1 \times$ Immobuffer, $2.5 \mathrm{mM} \mathrm{MgCl} 2,100 \mu \mathrm{M}$ dNTPs, $150 \mathrm{nM} F$. pseudograminearum CAL Fluor Gold labeled probe, $150 \mathrm{nM}$ wheat FAM labeled probe (Biosearch Technologies, Novato, CA), $0.25 \mu \mathrm{M}$ forward and reverse primers (Invitrogen, Mulgrave, VIC) for both targets, and $5 \mu 1$ of DNA template.

Controls in every assay included duplicate no template controls (NTC) and genomic DNA standards (positive/negative) for both $F$. pseudograminearum and wheat. Genomic DNA standards were produced by extracting DNA from a dry weight of pure $F$. pseudograminearum mycelium $(2.5 \mathrm{mg})$ or wheat tissue $(20 \mathrm{mg})$. Standards, run in triplicate, were diluted into four 10-fold serial dilutions for $F$. pseudograminearum DNA and three 10-fold serial dilutions for wheat DNA. Sample quantitative PCR values were normalized by dividing the estimated weight of $F$. pseudograminearum by the weight of extracted tissue (F. pseudograminearum mycelium [mg] / dry weight of tissue $[\mathrm{g}])$.

Tissue preparation, staining, and microscopic observation. Prior to drying, transverse sections of culm tissues were taken from the EGA Bellaroi and Hyperno samples in 2014 at 1, 7, and $13 \mathrm{~cm}$ in each culm by hand-sectioning using a microtome blade (S35, Feather, Japan). Fragile tissues, such as heavily infected culms, were hand-sectioned between two pieces of Parafilm (Frohlich 1984). Sections were stained using the solophenyl flavine-based fluorescence method described by Knight and Sutherland (2011). Tissues were viewed under a fluorescence microscope using a UV-2A filter (excitation filter, $330-380 \mathrm{~nm}$; dichroic mirror, $400 \mathrm{~nm}$; barrier filter, $420 \mathrm{~nm}$ ) (Eclipse E600, Nikon, Japan). Images were captured using a digital camera (DP26, Olympus, Japan) in conjunction with associated software (cellSens, Olympus, Japan). Presence and location of hyphae was noted. Vascular colonization was recorded for large vascular bundles (those not in the sclerenchymatous hypoderm) as presence or absence of at least a single hyphae in the xylem, phloem, or both xylem and phloem. The depth of the parenchymatous hypoderm was also collected from four positions in each culm section.

Variables and scales of measurement. Visual discoloration and $F$. pseudograminearum biomass were measured on four culm sections, 0 to $6 \mathrm{~cm}, 6$ to $12 \mathrm{~cm}, 12$ to $18 \mathrm{~cm}$, and the top $6 \mathrm{~cm}$ of peduncle, while vascular colonization and hypoderm depth were measured at three section heights above the crown, $1 \mathrm{~cm}, 7 \mathrm{~cm}$, and $13 \mathrm{~cm}$. All variables were assessed on two culm conditions, prematurely senescent culms and nonsenescent culms, aside from hypoderm depth where culm condition was not compared. Visual assessment of discoloration was performed on the surface area of entire $6 \mathrm{~cm}$ lengths

Table 1. Number of plants and culms collected and variables measured for each data set

\begin{tabular}{|c|c|c|c|c|c|}
\hline & \multicolumn{5}{|c|}{ Data set } \\
\hline & 2011 & 2012 & 2013 & 2014 & 2014 \\
\hline Cultivar & EGA Bellaroi & EGA Bellaroi & EGA Bellaroi & EGA Bellaroi & Hyperno \\
\hline Location & Wellcamp & Wellcamp & Wellcamp & Wellcamp & Narrabri \\
\hline Plant number & 17 & 20 & 20 & 28 & 12 \\
\hline Nonsenescent culms & 21 & 43 & 39 & 32 & 13 \\
\hline Prematurely senescent culms & 22 & 26 & 20 & 32 & 14 \\
\hline Culm discoloration & Yes & Yes & Yes & Yes & Yes \\
\hline Fusarium pseudograminearum biomass & Yes & Yes & Yes & Yes & Yes \\
\hline Peduncle & No & Yes & Yes & Yes & Yes \\
\hline Vascular colonization & No & No & No & Yes & Yes \\
\hline Hypoderm thickness & No & No & No & Yes & Yes \\
\hline
\end{tabular}


of culm using a $10 \%$ scale $(0,1-10,11-20,21-30,31-40,41-50,51-60$, $61-70,71-80,81-90,91-100)$. Any brown discoloration was considered due to crown rot in the rating procedure. F. pseudograminearum biomass was described as F. pseudograminearum mycelium (mg)/ dry weight of tissue (g), while hypoderm depth was measured in micrometers $(\mu \mathrm{m})$. Vascular colonization was recorded as vascular bundle counts for each type of colonization: xylem colonization, phloem colonization, xylem and phloem colonization, and no colonization. During analysis, these counts were converted to a percentage of total vascular bundles in each section.

Data analysis. Visual discoloration and $F$. pseudograminearum biomass were analyzed for each field sample separately (EGA Bellaroi in 2011, 2012, 2013, and 2014 and Hyperno in 2014), while hypoderm depth and vascular colonization were only analyzed for EGA Bellaroi in 2014 and Hyperno in 2014. To ensure homogeneity of variance, $\log$, square root, and logit transformations were applied to $F$. pseudograminearum biomass, hypoderm depth, and vascular colonization, respectively.

The analysis of each variable was performed using a linear mixed model. Model one for $F$. pseudograminearum biomass and visual discoloration included culm section, stem position, and their interaction, plus additional fixed effects for culm condition and the interaction between culm condition and all other fixed effects in the model. Model two for vascular colonization included the fixed effects from Model one, replacing culm section with culm height, with the addition of a term to account for type of colonization, along with the interactions between this effect and all other fixed effects in the model. The sampling factors for plant, culm section/section height within plant, culm within plant, and culm section within culm within plant were fitted as random effects for all variables. Additionally, in model two, the random terms were estimated separately for each type of colonization. Interaction effects involving culm condition and stem position were not fitted for the 2013 models or the 2014 Hyperno models due to high levels of imbalance in the data. Model three for hypoderm depth included fixed effects for section height, stem position, and their interaction.

Variance parameters were estimated using residual maximum likelihood (REML) estimation (Patterson and Thompson 1971). Prediction of fixed effect means were generated from the model as empirical best linear unbiased estimators (eBLUEs). The analysis was performed using ASReml-R (Butler et al. 2009) in the R software environment (R Core Team 2014). Significance of fixed effects were assessed using a Wald test with a value of $\alpha=0.05$.

The correlations between $F$. pseudograminearum biomass and visual discoloration and between $F$. pseudograminearum biomass and vascular colonization were analyzed using a bivariate linear mixed model for each field sample in which the variables were measured.
In the model, variable was fitted as a fixed effect, where variable refers to $F$. pseudograminearum biomass, visual discoloration, or vascular colonization, and separate terms for plant and culm section within plant for each variable, were fitted as random effects. An unstructured variance model was applied to the residual errors, which allowed for the estimation of a variance for each variable and the covariance between the two variables at each culm section by culm condition combination. Correlations between visual discoloration and vascular bundle colonization could not be calculated due to limited variation in the visual discoloration ratings.

\section{Results}

Observations of crown rot symptom development. Timing of sample collection each year varied according to the development of plants and disease, environmental conditions, planting times, and disease expression. The number of plants and variables measured for each data set are outlined in Table 1. EGA Bellaroi was collected during milk development in each year (growth stage 70-79, Zadoks et al. 1974). In 2011 and 2014, EGA Bellaroi plants were in the early stages of exhibiting prematurely senescent culm symptoms, indicated by a loss of greenness restricted mostly to the head, along with culms still appearing green along much of their length but exhibiting a limited loss of greenness in the peduncle. EGA Bellaroi samples in 2012 and 2013 appeared less green than in 2011 and 2014, which may indicate that they were later in the disease process. Hyperno plants collected in 2014 were collected slightly later in their development, when some plants in the crop were in late dough development (growth stage 80-89, Zadoks et al. 1974). The inclusion of Hyperno enabled assessment of prematurely senescent culms from a separate location and host cultivar.

Visual assessment of prematurely senescent culm formation indicated that loss of greenness was initiated in the head, with this symptom continuing down into the peduncle. Frequently, the flag leaf of these culms had a loss of greenness and was curling, with an apparent dryness. The loss of greenness continued down the culm, but became more difficult to discern at locations along the culm that were naturally less green than the peduncles, such as internodes covered by leaf sheaths. Culms considered nonsenescent did not exhibit loss of greenness in the head or any subtending sections of the culm.

Rating of the discoloration of each 6-cm culm portion, due to disease, indicated that the brown hue present due to crown rot varied between positions in the culm, and in some cases within a region of culm tissue. Vertical strips of discoloration were also observed on one side of some culms while the opposite side was not discolored.

Visual discoloration. Visual discoloration was greater in prematurely senescent culms than in nonsenescent culms for the three culm sections in all datasets (Table 2). The peduncle did not exhibit any

Table 2. Visual discoloration (\%) of each culm section of nonsenescent and senescent culm conditions. Mean discoloration ratings of each section were compared for each cultivar within each year (LSD indicated in brackets). Significant interactions between culm condition and culm section were not observed in 2014.

\begin{tabular}{|c|c|c|c|c|c|c|c|c|}
\hline & & \multicolumn{7}{|c|}{ Visual discoloration (\%) } \\
\hline & & 2011 & 2012 & 2013 & & & & \\
\hline & EGA Bellaroi & EGA Bellaroi & EGA Bellaroi & \multicolumn{2}{|c|}{ EGA Bellaroi } & \multicolumn{2}{|c|}{ Hyperno } \\
\hline$n$ & & 43 & 69 & 59 & \multicolumn{2}{|c|}{64} & \multicolumn{2}{|c|}{27} \\
\hline $\mathrm{CC} \times \mathrm{CS}$ or $\mathrm{CS}^{\mathrm{a}}$ & & $\mathrm{CC} \times \mathrm{CS}$ & $\mathrm{CC} \times \mathrm{CS}$ & $\mathrm{CC} \times \mathrm{CS}$ & $\mathrm{CC} \times \mathrm{CS}$ & CS & $\mathrm{CC} \times \mathrm{CS}$ & CS \\
\hline Culm section $(\mathrm{cm})$ & Culm condition & $P=0.028$ & $P=0.005$ & $P=0.012$ & - & $P<0.001$ & - & $P<0.001$ \\
\hline \multirow[t]{2}{*}{$0-6$} & Nonsenescent & 51.5 (b) & 64.2 (b) & 40.8 (b) & 94.3 & \multirow{2}{*}{97.5 (a) } & 85.8 & \multirow[b]{2}{*}{92.5 (a) } \\
\hline & Senescent & 82.9 (a) & 91.9 (a) & 70.5 (a) & 100.9 & & 98.8 & \\
\hline \multirow[t]{2}{*}{$6-12$} & Nonsenescent & $15.9(\mathrm{c})$ & 33.7 (c) & $22.3(\mathrm{c})$ & 47.7 & \multirow{2}{*}{50.9 (b) } & 72.5 & \multirow{2}{*}{79.2 (a) } \\
\hline & Senescent & 53.5 (b) & $52.6(\mathrm{~b})$ & 46.5 (b) & 54.3 & & 85.5 & \\
\hline \multirow[t]{2}{*}{$12-18$} & Nonsenescent & $2.5(\mathrm{~d})$ & $9.5(\mathrm{de})$ & $11.0(\mathrm{~d})$ & 23.2 & \multirow{2}{*}{$26.4(\mathrm{c})$} & 24.2 & \multirow{2}{*}{30.9 (b) } \\
\hline & Senescent & $19.6(\mathrm{c})$ & $18.6(\mathrm{~d})$ & $22.5(\mathrm{c})$ & 29.9 & & 37.2 & \\
\hline \multirow[t]{2}{*}{ Top $6^{\mathrm{b}}$} & Nonsenescent & - & $0.0(\mathrm{e})$ & $0.3(\mathrm{e})$ & -3.2 & \multirow{2}{*}{0 (d) } & -6.7 & \multirow{2}{*}{$0(\mathrm{c})$} \\
\hline & Senescent & - & $0.1(\mathrm{e})$ & $0.0(\mathrm{e})$ & 3.4 & & 6.3 & \\
\hline
\end{tabular}

${ }^{a} \mathrm{CC} \times \mathrm{CS}=$ interaction between culm condition and culm section; $\mathrm{CS}=$ means for the significant effects of culm section, averaged over culm condition.

${ }^{\mathrm{b}}$ True values for the top $6 \mathrm{~cm}$ of the peduncle were $0 \%$ in all datasets. Nonzero values presented for the top $6 \mathrm{~cm}$ are the result of the statistical modeling method used to compare the datasets. 
visual discoloration. There was a significant interaction between culm condition (prematurely senescent or nonsenescent) and culm section in $2011(P=0.028), 2012(P=0.005)$, and $2013(P=0.012)$.

There was not a significant interaction between culm condition and culm section for EGA Bellaroi or Hyperno in 2014. Visual discoloration of EGA Bellaroi in 2014 exhibited a significant effect for culm section $(P<0.001)$ (Table 2$)$.

Visual discoloration of Hyperno in 2014 exhibited a significant effect for culm section $(P<0.001)$ (Table 2$)$ and a significant effect for culm condition $(P=0.009)$ : nonsenescent culms $(44 \%)$ and prematurely senescent culms $(57 \%)$.

F. pseudograminearum biomass. $F$. pseudograminearum biomass was greater in prematurely senescent culms than nonsenescent culms in the three culm sections in all datasets (Table 3). There was a significant interaction between culm condition and culm section for EGA Bellaroi in 2011 and $2014(P<0.001)$.

There was not a significant interaction for $F$. pseudograminearum biomass between culm condition and culm section for EGA Bellaroi in 2012 and 2013 or Hyperno in 2014. F. pseudograminearum biomass in EGA Bellaroi in 2012 and 2013 exhibited a significant effect for culm section $(P<0.001)$ (Table 3$)$.

$F$. pseudograminearum biomass in Hyperno in 2014 exhibited a significant effect for culm section $(P<0.001)$ (Table 3$)$ and for culm condition $(P<0.001)$ : nonsenescent culms $(1 \mathrm{mg} / \mathrm{g})$ and prematurely senescent culms $(2.3 \mathrm{mg} / \mathrm{g})$.

Peduncle colonization. Detectable levels of $F$. pseudograminearum in the peduncle were low, infrequent, and did not show an association with prematurely senescent culms. In 2012 and 2013, 6 and $15 \%$ of peduncles had detectable levels of $F$. pseudograminearum, respectively, with a maximum of $0.01 \mathrm{mg}$ of $F$. pseudograminearum mycelium per gram of host tissue (data value prior to statistical analysis). No F. pseudograminearum was detected in the peduncles of plants collected in 2014.

Vascular colonization. Vascular bundle colonization was greater in prematurely senescent culms than nonsenescent culms in the three culm sections of EGA Bellaroi and Hyperno in 2014 (Table 4). There was a significant interaction between culm condition and section height $(P=0.005)$ for EGA Bellaroi in 2014. Vascular bundle colonization in Hyperno in 2014 exhibited a significant effect for culm condition $(P=0.012)$ and a significant effect for section height $(P=0.021)$ (Table 4).

Separation of vascular bundle colonization into those with no colonization, xylem colonization, or xylem and phloem colonization for EGA Bellaroi and Hyperno in 2014 demonstrated that each vascular bundle tissue in all prematurely senescent culm sections had greater colonization than the equivalent nonsenescent culm section (Table 4). Colonization of nonsenescent culms followed the pattern of greatest vascular bundle colonization at $1 \mathrm{~cm}$ and decreasing at
7 to $13 \mathrm{~cm}$. Prematurely senescent culms varied in their colonization patterns, with some more distal culm sections having higher levels of vascular colonization than sections lower on the culm. Vascular bundles just exhibiting colonized phloem could not be included in the analysis due to large numbers of zero values.

There was a significant interaction between section height, site of colonization, and culm condition $(P<0.001)$ for EGA Bellaroi. Prematurely senescent culms also exhibited increased numbers of vascular bundles with colonization of both the xylem and phloem at 1 and $13 \mathrm{~cm}$. Vascular colonization in Hyperno exhibited significant interactions between type of colonization and culm condition $(P=0.001)$ and between section height and type of colonization $(P<0.001)$ (Table 4).

General colonization of culm tissues included the presence of hyphae in the epidermal cells, parenchymatous hypoderm, schlerenchymatous hypoderm, and pith parenchyma. The presence of hyphae in each of these regions varied between sections, but colonization of the vascular bundles alone was not observed.

Correlation of disease measurement methods. Correlations between visual discoloration and $F$. pseudograminearum biomass varied with culm condition and culm section (Table 5). The most consistently high correlation values were reported for the $0-6 \mathrm{~cm}$ section.

Correlations of $F$. pseudograminearum biomass and vascular bundle colonization determined using a bivariate linear mixed model ranged from 0.51 to 0.96 in the $0-6 \mathrm{~cm}$ culm section of nonsenescent and prematurely senescent culms of EGA Bellaroi and Hyperno in 2014 (Table 6). Correlations in the 6-12 cm and 12-18 cm culm sections exhibited a wider range of values and were generally lower than the $0-6 \mathrm{~cm}$ section correlations.

Hypoderm depth. There was a significant effect for section height in both cultivars $(P<0.001)$. The depth of parenchymatous hypoderm tissue decreased significantly from 1 to $7 \mathrm{~cm}$ and from 7 to $13 \mathrm{~cm}$ above the crown in the culms of both EGA Bellaroi and Hyperno (Table 7). No difference in hypoderm depth was indicated between prematurely senescent and nonsenescent culms.

\section{Discussion}

This investigation has provided a unique field comparison of durum wheat culms exhibiting moderate and extreme disease symptoms of Fusarium crown rot. It is the first study to extensively measure the degree of vascular colonization in diseased tissues, and clearly demonstrates that prematurely senescent durum wheat culms exhibit increased vascular colonization, visual discoloration, and $F$. pseudograminearum biomass compared with nonsenescent culms. The estimation of vascular bundle colonization, together with quantitative PCR estimation of fungal biomass at several points along a length of diseased culm, suggests distinct patterns of fungal growth

Table 3. Fusarium pseudograminearum biomass (mg/g) of each culm section of nonsenescent and senescent culm conditions. Mean F. pseudograminearum biomass quantities of each section were compared for each cultivar within each year (LSD indicated in brackets). Significant interactions between culm condition and culm section were not observed for EGA Bellaroi in 2012 and 2013 or Hyperno in 2014.

\begin{tabular}{|c|c|c|c|c|c|c|c|c|c|}
\hline & & \multicolumn{8}{|c|}{ F. pseudograminearum biomass (mg/g) } \\
\hline & & 2011 & \multicolumn{2}{|c|}{2012} & \multicolumn{2}{|c|}{2013} & 2014 & \multicolumn{2}{|c|}{2014} \\
\hline Cultivar & & EGA Bellaroi & \multirow{2}{*}{\multicolumn{2}{|c|}{$\begin{array}{c}\text { EGA Bellaroi } \\
69\end{array}$}} & \multirow{2}{*}{\multicolumn{2}{|c|}{$\begin{array}{c}\text { EGA Bellaroi } \\
59\end{array}$}} & EGA Bellaroi & \multirow{2}{*}{\multicolumn{2}{|c|}{$\begin{array}{c}\text { Hyperno } \\
27\end{array}$}} \\
\hline$n$ & & 43 & & & & & 64 & & \\
\hline $\mathrm{CC} \times \mathrm{CS}$ or $\mathrm{CS}^{\mathrm{a}}$ & & $\mathrm{CC} \times \mathrm{CS}$ & $\mathrm{CC} \times \mathrm{CS}$ & CS & $\mathrm{CC} \times \mathrm{CS}$ & CS & $\mathrm{CC} \times \mathrm{CS}$ & $\mathrm{CC} \times \mathrm{CS}$ & CS \\
\hline Culm section $(\mathrm{cm})$ & Culm condition & $P<0.001$ & - & $P<0.001$ & - & $P<0.001$ & $P<0.001$ & - & $P<0.001$ \\
\hline $0-6$ & $\begin{array}{l}\text { Nonsenescent } \\
\text { Senescent }\end{array}$ & $\begin{array}{r}6.0(\mathrm{~b}) \\
13.8(\mathrm{a})\end{array}$ & $\begin{array}{r}8.7 \\
12.5\end{array}$ & 10.0 (a) & $\begin{array}{r}7.8 \\
10.2\end{array}$ & 8.6 (a) & $\begin{array}{l}3.9(\mathrm{~b}) \\
9.7(\mathrm{a})\end{array}$ & $\begin{array}{l}2.2 \\
4.3\end{array}$ & 3.1 (a) \\
\hline $6-12$ & $\begin{array}{l}\text { Nonsenescent } \\
\text { Senescent }\end{array}$ & $\begin{array}{r}2.0(\mathrm{c}) \\
17.3(\mathrm{a})\end{array}$ & $\begin{array}{l}5.5 \\
8\end{array}$ & $6.4(b)$ & $\begin{array}{l}6.5 \\
8.6\end{array}$ & 7.2 (a) & $\begin{array}{r}2.5(\mathrm{~b}) \\
10.6(\mathrm{a})\end{array}$ & $\begin{array}{l}2.5 \\
4.8\end{array}$ & 3.5 (a) \\
\hline $12-18$ & $\begin{array}{l}\text { Nonsenescent } \\
\text { Senescent }\end{array}$ & $\begin{array}{c}0.7(\mathrm{~d}) \\
11.1(\mathrm{ab})\end{array}$ & $\begin{array}{l}3.2 \\
4.8\end{array}$ & $3.8(\mathrm{c})$ & $\begin{array}{l}2.6 \\
3.6\end{array}$ & 2.9 (b) & $\begin{array}{l}0.2(\mathrm{c}) \\
3.0(\mathrm{~b})\end{array}$ & $\begin{array}{l}1.5 \\
3\end{array}$ & $2.1(\mathrm{a})$ \\
\hline Top $6^{\mathrm{b}}$ & $\begin{array}{l}\text { Nonsenescent } \\
\text { Senescent }\end{array}$ & $\begin{array}{l}- \\
-\end{array}$ & $\begin{array}{r}-0.1 \\
0.1\end{array}$ & $0(\mathrm{~d})$ & $\begin{array}{l}0 \\
0.1\end{array}$ & $0(\mathrm{c})$ & $\begin{array}{l}0.0(\mathrm{c}) \\
0.0(\mathrm{c})\end{array}$ & $\begin{array}{r}-0.1 \\
0.1\end{array}$ & 0 (b) \\
\hline
\end{tabular}

${ }^{a} \mathrm{CC} \times \mathrm{CS}=$ interaction between culm condition and culm section; CS = means for the significant effects of culm section, averaged over culm condition.

${ }^{b}$ Negative values presented for the top $6 \mathrm{~cm}$ of the peduncle are the result of the statistical modeling method used to compare the datasets. 
during disease progression, particularly the dynamic nature of infection intensity at different points along the culm and the ability of $F$. pseudograminearum to densely colonize vascular bundles up to at least $18 \mathrm{~cm}$ above the crown.

Prematurely senescing culms have been frequently used in crown rot assessment methods (Burgess et al. 1975; Hollaway and Exell 2010; Klein et al. 1991; McKnight and Hart 1966; Purss 1966); however, to date, there has been limited examination of the disease aspects leading to this condition. Purss (1966) reported that culms of spring wheat with ears classified as healthy had a high percentage of infection in the third internode; however, a greater level of infection was present in the third and fourth internodes in prematurely senescing culms. Klaasen et al. (1992), in a South African study on winter wheat, also reported that $F$. pseudograminearum was isolated significantly more frequently from plants with prematurely senescing culms than those with healthy heads and that plants with prematurely senescing culms had greater visual discoloration. Burgess et al. (2001) suggested that prematurely senescing culm formation may occur due to hyphal disruption of water transport from the root system to the head, an idea that has been supported by the current study, where frequent xylem colonization was observed. Specifically, the proportion of vascular bundles colonized may be the determining factor in the production of a prematurely senescent culm. Nonsenescent culms generally exhibited a low level of colonization of vascular bundles compared with prematurely senescent culms, which had significantly greater colonization of their vascular bundles up to $13 \mathrm{~cm}$ above the base of the culm. The trigger to induce premature senescence in a diseased culm may involve a response by $F$. pseudograminearum to a loss of moisture, causing it to rapidly colonize extensive portions of the culm. A similar response of increased colonization at lower water potentials has previously been reported in wheat seedlings (Beddis and Burgess 1992).

The first study to provide detailed observations of the colonization of cereal culms by $F$. pseudograminearum was recently reported by Knight and Sutherland (2016). The current study of durum wheat has extended these observations over multiple trials and quantified the colonization of xylem and phloem tissues in nonsenescent and prematurely senescent culms exhibiting crown rot disease. These results indicate that xylem tissues are the initial, and most frequently, colonized tissue of the vascular bundles, with phloem colonization becoming more frequent in bundles in the prematurely senescent

Table 5. Correlations (bivariate linear mixed model) between visual discoloration and Fusarium pseudograminearum biomass in nonsenescent and senescent culms for each culm section

\begin{tabular}{lllrrr}
\hline & & & \multicolumn{3}{c}{ Culm section $(\mathbf{c m})$} \\
\cline { 4 - 6 } Cultivar & \multirow{2}{*}{ Year } & Culm condition & $\mathbf{0 - 6}$ & $\mathbf{6 - 1 2}$ & $\mathbf{1 2 - 1 8}$ \\
\hline EGA Bellaroi & \multirow{2}{*}{2011} & Nonsenescent & 0.28 & 0.6 & 0.09 \\
& & Senescent & -0.27 & 0.68 & 0.89 \\
EGA Bellaroi & \multirow{2}{*}{2012} & Nonsenescent & 0.74 & -0.03 & -0.38 \\
& & Senescent & 0.22 & 0.19 & 0.55 \\
EGA Bellaroi & \multirow{2}{*}{2013} & Nonsenescent & 0.49 & 0.08 & 0.34 \\
& \multirow{2}{*}{ Hyperno } & Senescent & 0.47 & 0.12 & 0.16 \\
& \multirow{2}{*}{2014} & Nonsenescent & 0.71 & 0.31 & 0.41 \\
& & Senescent & $-\mathrm{a}$ & $-\mathrm{a}$ & 0.81 \\
\hline
\end{tabular}

a No correlation due to insufficient variation.

Table 4. Fusarium pseudograminearum colonization of the xylem and phloem of vascular bundles in nonsenescent and senescent culm sections of EGA Bellaroi and Hyperno in 2014. Colonization assessment included percentage of vascular bundles with hyphal colonization (combined) and separated colonization percentage of bundles with no hyphal colonization and bundles with at least one hyphae in xylem, phloem, or both xylem and phloem tissues. Mean colonization (\%) values of each section and tissue were compared for the significant interaction between culm condition and culm section in EGA Bellaroi (LSD indicated in brackets). A significant interaction between culm condition and culm section was not observed for Hyperno.

\begin{tabular}{|c|c|c|c|c|c|c|}
\hline \multirow[t]{3}{*}{ Colonization type } & \multirow{3}{*}{$n$} & \multicolumn{2}{|c|}{ EGA Bellaroi } & \multicolumn{3}{|c|}{ Hyperno } \\
\hline & & & & & 27 & \\
\hline & & Nonsenescent & Senescent & Nonsenescent & Senescent & $\mathrm{CS}^{\mathrm{b}}$ \\
\hline & Section height $(\mathrm{cm})^{\mathrm{a}}$ & \multicolumn{2}{|c|}{$P=0.005$} & \multicolumn{2}{|c|}{-} & $P=0.021$ \\
\hline \multirow[t]{7}{*}{ Vascular colonization (combined) } & 1 & 13.9 (c) & $76.8(\mathrm{a})$ & 13.6 & 32.1 & 22 (a) \\
\hline & 7 & $10.8(\mathrm{~cd})$ & 34.4 (b) & 16.5 & 36.2 & 25.5 (a) \\
\hline & \multirow[t]{2}{*}{13} & $4.6(d)$ & $50.4(b)$ & 2.2 & 14.1 & $7.3(b)$ \\
\hline & & - & - & \multicolumn{2}{|c|}{$P=0.012$} & - \\
\hline & \multirow[t]{3}{*}{$\mathrm{CC}^{\mathrm{c}}$} & \multirow{2}{*}{\multicolumn{2}{|c|}{-}} & 9.9 (a) & $26.6(b)$ & - \\
\hline & & & & & & $\mathrm{SH} \times \mathrm{TC}^{\mathrm{d}}$ \\
\hline & & \multicolumn{2}{|c|}{$P<0.001$} & \multicolumn{2}{|c|}{-} & $P<0.001$ \\
\hline \multirow[t]{3}{*}{ No colonization } & 1 & 86.1 (b) & 23.2 (ef) & 86.4 & 67.9 & 78 (b) \\
\hline & 7 & $89.2(a b)$ & $65.6(\mathrm{c})$ & 83.6 & 63.9 & 74.5 (b) \\
\hline & 13 & 95.4 (a) & $49.6(\mathrm{~cd})$ & 95.3 & 86.2 & 92.8 (a) \\
\hline \multirow[t]{3}{*}{ Xylem and phloem } & 1 & 4.8 (hi) & $49.6(\mathrm{c})$ & 5.8 & 17.9 & $11.2(\mathrm{c})$ \\
\hline & 7 & 3.4 (hi) & 8.8 (ghi) & 4.6 & 16 & 9.7 (cd) \\
\hline & 13 & 1.8 (i) & 33.7 (de) & 1 & 6.7 & $2.3(\mathrm{e})$ \\
\hline \multirow[t]{4}{*}{ Xylem } & 1 & $8.3(\mathrm{~h})$ & $15.4(\mathrm{fg})$ & 6.5 & 8.5 & $7.7(\mathrm{~cd})$ \\
\hline & 7 & 6.8 (hi) & 21.1 (f) & 10.6 & 13 & $11.8(\mathrm{c})$ \\
\hline & 13 & 2.8 (i) & $8.3(\mathrm{~h})$ & 3.7 & 5.4 & $4.5(\mathrm{de})$ \\
\hline & 1 & 0.8 & 11.8 & 1.3 & 5.7 & - \\
\hline \multirow[t]{3}{*}{ Phloem $^{\mathrm{e}}$} & 7 & 0.6 & 4.5 & 1.2 & 7.1 & - \\
\hline & 13 & 0 & 8.4 & 0 & 1.8 & - \\
\hline & & \multicolumn{2}{|c|}{ - } & \multicolumn{2}{|c|}{$P=0.001$} & - \\
\hline No colonization & $\mathrm{CC} \times \mathrm{TC}^{\mathrm{f}}$ & - & - & 90.2 (a) & 73.5 (b) & - \\
\hline Xylem and phloem & $\mathrm{CC} \times \mathrm{TC}^{\mathrm{f}}$ & - & - & $2.8(\mathrm{e})$ & $13.1(\mathrm{c})$ & - \\
\hline Xylem & $\mathrm{CC} \times \mathrm{TC}^{\mathrm{f}}$ & - & - & $6.7(\mathrm{de})$ & $8.8(\mathrm{~cd})$ & - \\
\hline
\end{tabular}

a Section height above the crown.

${ }^{\mathrm{b}}$ Means for the significant effects of culm section (CS) in Hyperno, averaged over culm condition.

${ }^{c}$ Means for the significant effects of culm condition (CC) in Hyperno, averaged over section height.

${ }^{\mathrm{d}}$ Means for the significant interactions between section height (SH) and type of colonization (TC) in Hyperno, averaged over culm condition.

e Phloem colonization was omitted from analysis due to a high number of zero scores.

${ }^{\mathrm{f}}$ Means for the significant interactions between culm condition (CC) and type of colonization (TC) in Hyperno, averaged over section height. 
culms. In these culms, a vascular bundle will more frequently have hyphae in both xylem and phloem tissues, which suggests the possibility of fungal disruption of both water and sugar flow in the culm. Physiological studies of plants affected by crown rot disease are required to shed further light on the extent to which xylem and phloem colonization compromises transpiration flow and nutrient transport.

The method applied in the current study utilized durum wheat due to its susceptibility to crown rot, the high frequency of prematurely senescent culm symptoms, and its value as a commercial cereal crop. The technique of rating disease based on 6-cm sections was designed by the authors to encompass the first three internodes, typically used for crown rot rating due to their distinct visual discoloration (Purss 1966), in the first section and a further two sections of $6 \mathrm{~cm}$, up to $18 \mathrm{~cm}$, to record colonization higher in the culm. The 6-cm sections were also the most practical for DNA extraction and quantitative PCR. A modified visual rating scale based on $10 \%$ increments of discoloration was employed as it captured and compared a range of disease reactions and is a preferred method for rating systems that employ a category scale (Chiang et al. 2016). Assessment of the basal $0-18 \mathrm{~cm}$ of culm tissue in three sections indicated variation in $F$. pseudograminearum colonization along the culm, most likely due to the timing of colonization and environmental conditions. Colonization of the peduncle was infrequently observed in the current study and has only previously been reported in mature wheat plants (Malligan 2009; Purss 1966). This study has indicated that, in general, visual discoloration, $F$. pseudograminearum biomass, and vascular colonization decrease in tissues further up the culm. Interestingly, unlike visual discoloration, which is a static measure of disease, $F$. pseudograminearum biomass and vascular colonization indicated the current levels of colonization in culm sections and demonstrated that given favorable conditions, $F$. pseudograminearum could colonize culm sections higher than 0-6 cm more densely. For example, the prematurely senescent culms of EGA Bellaroi in 2011 and 2014 , which were early in the senescing process, had greater mean levels of $F$. pseudograminearum biomass in the $6-12 \mathrm{~cm}$ than 0-6 cm sections. This indicates that a colonization front of $F$. pseudograminearum hyphae may occur along a significant portion of a culm, with more profuse growth occurring in regions where nutrients are more readily available, and a possible decrease in hyphae at later time points due to nutrient depletion and senescing tissues, particularly in

Table 6. Correlations (bivariate linear mixed model) between Fusarium pseudograminearum biomass and percentage of vascular bundle colonization in nonsenescent and senescent culms for each culm section

\begin{tabular}{lllccc}
\hline & & & \multicolumn{3}{c}{${\text { Culm section }(\mathbf{c m})^{\mathbf{a}}}$} \\
\cline { 4 - 6 } Cultivar & Year & Culm condition & $\mathbf{0 - 6}$ & $\mathbf{6 - 1 2}$ & $\mathbf{1 2 - 1 8}$ \\
\hline EGA Bellaroi & \multirow{2}{*}{2014} & Nonsenescent & 0.51 & 0.54 & 0.93 \\
& & Senescent & 0.88 & 0.36 & 0.68 \\
Hyperno & \multirow{2}{*}{2014} & Nonsenescent & 0.96 & 0.42 & 0.8 \\
& & Senescent & 0.76 & 0.65 & 0.45 \\
\hline
\end{tabular}

a The terms culm section and section height are considered synonymous for this analysis.

Table 7. Hypoderm depth at three positions in culms in 2014. Mean hypoderm depth $(\mu \mathrm{m})$ was compared between each position in a culm for EGA Bellaroi and Hyperno (LSD indicated in brackets).

\begin{tabular}{lcc}
\hline & \multicolumn{2}{c}{ Hypoderm depth $(\boldsymbol{\mu m})^{\mathbf{a}}$} \\
\hline Cultivar & EGA Bellaroi & Hyperno \\
$n$ & 64 & 27 \\
Section height $(\mathrm{cm})^{\mathrm{b}}$ & $P<0.001$ & $P<0.001$ \\
$\quad 1$ & $99.2(\mathrm{a})$ & $67.3(\mathrm{a})$ \\
7 & $19.5(\mathrm{~b})$ & $25.0(\mathrm{~b})$ \\
13 & $2.6(\mathrm{c})$ & $6.8(\mathrm{c})$ \\
\hline
\end{tabular}

\footnotetext{
${ }^{a}$ Hypoderm depth was measured at four positions in each culm section.
}

${ }^{\mathrm{b}}$ Section height above the crown. culm tissues more proximal to the crown (Knight et al. 2012; Knight and Sutherland 2015).

While visual discoloration due to browning of the parenchymatous hypoderm (Knight and Sutherland 2016) generally indicated differences between nonsenescent and prematurely senescent culms, the intensity of discoloration decreased with height above the crown in all culms assessed. This is consistent with the decrease in thickness of the parenchymatous hypoderm observed in cross sections more distal from the crown (Table 7; Knight and Sutherland 2016). While rating of visual discoloration may rely on the presence of parenchymatous hypoderm layers that vary within culms, it is consistently correlated to the colonization of the culm tissue, indicating its robustness as a disease assessment method. Significantly, correlations between fungal biomass and visual discoloration are lower for more distal culm sections and this may be related to the lower content of parenchymatous hypoderm in these tissues.

Field experiments involving disease assessment of crown rot across multiple years are frequently affected by environmental variation (Hogg et al. 2007). Statistical comparisons of each dataset in the current study were affected in this manner, which resulted in limited significant interactions in some years for visual discoloration and $F$. pseudograminearum biomass. This may also have been affected by timing of sample collection. Those samples that were collected early in the prematurely senescent culm formation process, such as culms of EGA Bellaroi in 2011 and 2014, exhibited the greatest differences between culm conditions, while the remaining samples, collected later in the formation process, expressed these differences at a lower magnitude. This indicates that the increased colonization involved with premature senescence may only persist for a short period of time.

This research has demonstrated that severity of crown rot disease in durum wheat culms can be successfully reported using visual discoloration, $F$. pseudograminearum biomass, and vascular colonization. Assessment of vascular colonization may be the most informative of these three methods and should be considered in future assessments of crown rot aimed at describing resistance and assessing pathophysiology in cereal hosts. A parallel assessment of spring wheat cultivars with prematurely senescent culms is currently being undertaken. Species-specific quantitative PCR also remains pivotal in confirming pathogen identity and biomass in future examinations. The increasing knowledge of the plant pathogen interactions involved in crown rot, particularly the colonization of vascular tissues, may soon lead to novel methods of assessing host reactions based on physiological responses, such as transpiration rates or leaf temperatures, which could provide one or more rapid methods for characterizing host reactions to crown rot and for selecting resistant materials.

\section{Acknowledgments}

The authors thank Dr. Cassandra Percy (Centre for Crop Health, University of Southern Queensland), Dr. Philip Davies (University of Sydney), and Dr. Anke Martin (Centre for Crop Health, University of Southern Queensland) for providing field samples. Financial support for this project was provided by both the University of Southern Queensland Strategic Research Fund and the Grains Research and Development Corporation.

\section{Literature Cited}

Beddis, A. L., and Burgess, L. W. 1992. The influence of plant water stress on infection and colonisation of wheat seedlings by Fusarium graminearum Group 1. Phytopathology 82:78-83.

Burgess, L. W., Backhouse, D., Summerell, B. A., and Swan, L. J. 2001. Crown rot of wheat. Pages 271-294 in: Fusarium: Paul E. Nelson Memorial Symposium, B. Summerell, J. Leslie, D. Backhouse, W. Bryden, and L. Burgess, eds. APS Press, St. Paul, MN.

Burgess, L. W., Wearing, A. H., and Toussoun, T. A. 1975. Surveys of Fusaria associated with crown rot of wheat in eastern Australia. Aust. J. Agric. Res. 26:791-799.

Butler, D., Cullis, B., Gilmour, A., and Gogel, B. 2009. ASReml-R reference manual. The State of Queensland. Department of Primary Industries and Fisheries, Brisbane, Australia.

Chiang, K. S., Bock, C. H., El Jarroudi, M., Delfosse, P., Lee, I. H., and Liu, H. I. 2016. Effects of rater bias and assessment method on disease severity estimation with regard to hypothesis testing. Plant Pathol. 65:523-535. 
Frohlich, M. W. 1984. Freehand sectioning with Parafilm. Stain Technol. 59: 61-62.

Hogg, A. C., Johnston, R. H., and Dyer, A. T. 2007. Applying real-time quantitative PCR to Fusarium crown rot of wheat. Plant Dis. 91:1021-1028.

Hollaway, G. J., and Exell, G. K. 2010. Survey of wheat crops for white heads caused by crown rot in Victoria, 1997-2009. Australas. Plant Pathol. 39: 363-367.

Klaasen, J. A., Matthee, F. N., Marasas, W. F. O., and van Schalkwyk, D. J. 1992. Survey of Fusarium species associated with crowns of healthy-head and whitehead wheat plants in the southern and western Cape Province. Phytophylactica 24:85-94.

Klein, T. A., Burgess, L. W., and Ellison, F. W. 1991. The incidence and spatial patterns of wheat plants infected by Fusarium graminearum Group 1 and the effect of crown rot on yield. Aust. J. Agric. Res. 42:399-407.

Knight, N. L., Martin, A., Sutherland, M. W., and Herde, D. J. 2012. Assessment of infection by Fusarium pseudograminearum in wheat seedling tissues using quantitative PCR and a visual discoloration scale. Plant Dis. 96:1661-1669.

Knight, N. L., and Sutherland, M. W. 2011. A rapid differential staining technique for Fusarium pseudograminearum in cereal tissues during crown rot infections. Plant Pathol. 60:1140-1143.

Knight, N. L., and Sutherland, M. W. 2012. Histopathological assessment of wheat seedling tissues infected by Fusarium pseudograminearum. Plant Pathol. 62: 679-687.

Knight, N. L., and Sutherland, M. W. 2015. Culm discolouration as an indicator of Fusarium pseudograminearum biomass. Australas. Plant Pathol. 44:319-326.

Knight, N. L., and Sutherland, M. W. 2016. Histopathological assessment of Fusarium pseudograminearum colonization of cereal culms during crown rot infections. Plant Dis. 100:252-259.
Malligan, C. D. 2009. Crown rot (Fusarium pseudograminearum) symptom development and pathogen spread in wheat genotypes with varying disease resistance. $\mathrm{PhD}$ thesis. University of Southern Queensland, Toowoomba, Australia

Martin, A., Simpfendorfer, S., Hare, R. A., and Sutherland, M. W. 2013. Introgression of hexaploid sources of crown rot resistance into durum wheat. Euphytica 192:463-470.

Matthews, P., McCaffery, D., and Jenkins, L. 2016. Winter crop variety sowing guide. Department of Primary Industries NSW, Orange, Australia.

McKnight, T., and Hart, J. 1966. Some field observations on crown rot disease of wheat caused by Fusarium graminearum. Queensl. J. Agric. Anim. Sci. 23:373-378.

Murray, G. M., and Brennan, J. P. 2009. Estimating disease losses to the Australian wheat industry. Australas. Plant Pathol. 38:558-570.

Patterson, H. D., and Thompson, R. 1971. Recovery of inter-block information when block sizes are unequal. Biometrika 58:545-554.

Percy, C. D., Wildemuth, G. B., and Sutherland, M. W. 2012. Symptom development proceeds at different rates in susceptible and partially resistan cereal seedlings infected with Fusarium pseudograminearum. Australas. Plant Pathol. 41:621-631.

Purss, G. S. 1966. Studies of varietal resistance to crown rot of wheat caused by Fusarium graminearum Schw. Queensl. J. Agric. Anim. Sci. 23:475-498.

R Core Team. 2014. R: A language and environment for statistical computing R Foundation for Statistical Computing, Vienna, Austria.

Sims, H., Meagher, J., and Millikan, C. 1961. Deadheads in wheat-field studies in Victoria. Anim. Prod. Sci. 1:99-108.

Wallwork, H. 2000. Cereal root and crown diseases. Grains Research and Development Corporation, Kingston, ACT, Australia.

Zadoks, J. C., Chang, T. T., and Konzak, C. F. 1974. A decimal code for the growth stages of cereals. Weed Res. 14:415-421. 